\title{
Effects of LDOC1 on colorectal cancer cells via downregulation of the Wnt/ $\beta$-catenin signaling pathway
}

\author{
JIAYI JIANG ${ }^{1}$, YOU LI $^{2}$ and ZHENG JIANG ${ }^{1}$ \\ Departments of ${ }^{1}$ Gastroenterology and ${ }^{2}$ Gastrointestinal Surgery, \\ The First Affiliated Hospital of Chongqing Medical University, Chongqing 400016, P.R. China
}

Received November 13, 2018; Accepted April 3, 2019

DOI: 10.3892/or.2019.7126

\begin{abstract}
Colorectal cancer (CRC) is one of the most common tumor types of the digestive tract. Its incidence and mortality rates are among the highest of all gastrointestinal tumor types. The expression of leucine zipper downregulated in cancer 1 (LDOC1) is decreased in numerous cancer types. In the present study, the aim was to investigate the role of LDOC1 and determine the potential molecular mechanisms of its action in CRC. The expression of LDOC1 in CRC tissues and adjacent normal tissues was detected by reverse transcription-quantitative polymerase chain reaction and immunohistochemistry. LDOC1 expression in four CRC cell lines, compared with normal colorectal tissue, was determined by reverse transcription- polymerase chain reaction (RT-PCR), and two cell lines with relatively low expression were screened. Human LDOC1 cDNA was inserted into a lentiviral vector, and transfected into HCT-116 and Caco 2 cell lines. The transfection efficiency was identified by RT-PCR and western blot analysis. Cell proliferation was detected by Cell Counting Kit- 8 and colony formation assays. Cell cycle and apoptosis were detected by flow cytometry assay. Migration and invasion were assessed using Transwell and Matrigel assays, respectively. Additionally, whether LDOC1 regulates the $\mathrm{Wnt} / \beta$-catenin pathway was investigated by western blot analysis, and the expression and localization of $\beta$-catenin in CRC cells were demonstrated by cellular immunofluorescence. LDOC1 expression was downregulated in CRC tissues and cells. LDOC1 overexpression inhibited cell proliferation, migration and invasion, but promoted cells apoptosis. Furthermore, LDOC1 downregulated the Wnt/ $\beta$-catenin
\end{abstract}

Correspondence to: Dr Zheng Jiang, Department of Gastroenterology, The First Affiliated Hospital of Chongqing Medical University, 1 Youyi Road, Chongqing 400016, P.R. China E-mail: jiangz1753@163.com

Abbreviations: CRC, colorectal cancer; RT-qPCR, reverse transcription-quantitative polymerase chain reaction; RT-PCR, reverse transcription-polymerase chain reaction; CCK8, Cell Counting Kit- 8

Key words: leucine zipper downregulated in cancer 1, colorectal cancer, metastasis, apoptosis, Wnt/ $\beta$-catenin pathway in CRC. In conclusion, LDOC1 is a tumor suppressor in CRC and it inhibits cell proliferation and promotes cell apoptosis. Additionally, it inhibits CRC cell metastasis by downregulating the $\mathrm{Wnt} / \beta$-catenin signaling pathway.

\section{Introduction}

Colorectal cancer (CRC) is one of the most common malignancy types globally (1). In the USA, from 2000-2013, although the morbidity and mortality rates of CRC have decreased in adults $\geq 50$ years of age, they have increased significantly in adults $<50$ years of age (2). According to the latest figures, there was an estimated 18.1 million new cases and 9.6 million cancer-associated mortalities globally in 2018. However, the global incidence $(6.1 \%)$ and mortality $(9.2 \%)$ rates of CRC in 2018 are the third and second highest, respectively, of all cancer types (3). The transition from normal epithelium to development of CRC is a process involving multiple genes, including the activation of pro-oncogenes and the inactivation of tumor suppressor genes (4). Therefore, identification of novel tumor markers and underlying molecular mechanisms may contribute to the diagnosis, treatment and prognosis of CRC.

The leucine zipper downregulated in cancer 1 (LDOC1) is a differentially-expressed gene identified by Nagasaki using the RNA differential display technique in cancer cells (5). It encodes a protein that has the leucine zipper-like motif and the SH3-binding domain that can regulate gene transcription and intracellular signal transduction (6). Previous studies indicated that LDOC1 expression is decreased in numerous cancer types, including papillary thyroid carcinoma, liver cancer and prostate cancer (6-11). As a tumor suppressor gene, it has been demonstrated to be involved in the regulation of the nuclear factor- $\kappa \mathrm{B}(\mathrm{NF}-\kappa \mathrm{B})$ signaling pathway in numerous cancer types, including papillary thyroid carcinoma, cervical cancer and pancreatic cancer, thereby promoting apoptosis and inhibiting proliferation of cancer cells $(6,12-13)$. The decreased expression of LDOC1 is also associated with methylation in ovarian and cervical cancer types $(14,15)$. Additionally, LDOC1 can regulate the release of inflammatory mediators and thus affect inflammation (11); however, the significance of LDOC1 expression for cancer metastasis and progression is rarely reported. Furthermore, only one publication has reported that $\mathrm{LDOC} 1$ may regulate the metastasis of osteosarcoma through the Wnt5a signaling pathway (16). Studies 
demonstrated that there is an indirect association between the Wnt5a and Wnt/ $\beta$-catenin signaling pathways $(17,18)$. It is well known that the $\mathrm{Wnt} / \beta$-catenin signaling pathway serves a crucial role in the development of numerous cancer types, including cervical, ovarian and lung cancer, particularly in invasion, migration and epithelial-mesenchymal transition (EMT) (19-21). A number of studies demonstrated that some genes, including PLAG1 like zinc finger 2, G protein nucleolar 3 and deleted in bladder cancer protein 1 , that regulate the $\mathrm{Wnt} / \beta$-catenin signaling pathway affect invasion, migration and EMT in CRC (22-24). However, the association between LDOC1 and the occurrence and development of CRC has not been reported, and the potential mechanisms of LDOC1 action in CRC have not been elucidated. Therefore, the aim of the present study was to investigate the LDOC1 expression and elucidate its molecular mechanism in CRC, thus providing a novel potential biomarker for CRC.

\section{Materials and methods}

Tissue samples and cell culture. A total of 14 fresh samples of CRC and paired adjacent normal colorectal tissue were collected from the Operation Room of the First Affiliated Hospital of Chongqing Medical University (Chongqing, China; June, 2017 to December, 2017) (Table I). Subsequently, the RNA was immediately extracted, which would be detected via reverse transcription-quantitative polymerase chain reaction (RT-qPCR), according to subsequent protocols. However, another 53 paraffin sections of CRC and normal tissue, which were obtained from the Department of Pathology of the First Affiliated Hospital of Chongqing Medical University (June, 2018 to September, 2018), were used for detecting the levels of proteins, via the subsequent immunohistochemistry protocols (Table II). Therefore, there is no overlap between the two groups of patients. All patients provided informed consent, and the present study was approved by the Ethics Committee of the First Affiliated Hospital of Chongqing Medical University. CRC cell lines (SW480, Caco2, HCT116 and HT29) were purchased from the American Type Culture Collection (Manassas, VA, USA). Cells were cultured in RPMI-1640 (HyClone; GE Healthcare Life Sciences, Logan, UT, USA) supplemented with $10 \%$ fetal bovine serum (cat. no. FSP500; ExCell Biology Inc., Shanghai, China) for 3 days in $5 \% \mathrm{CO}_{2}$ at $37^{\circ} \mathrm{C}$. The $\mathrm{Wnt} / \beta$-catenin pathway activator IM-12 (Selleck Chemicals, Houston, TX, USA) was added to culture medium $(1 \mu \mathrm{g} / \mathrm{ml})$. After $24 \mathrm{~h}$ post treatment at $37^{\circ} \mathrm{C}$, the total cell lysates were collected and protein level detected by western blotting, according to the subsequent protocol.

Cell transfection and puromycin screening. Human LDOC1 cDNA was amplified and inserted into a lentiviral vector (lentivirus titer, $2.1 \times 10^{8} \mathrm{TU} / \mathrm{ml}$ ). The recombinant lentiviral vector expressing LDOC1 (Lv-LDOC1) and the empty vector (Lv-NC) were purchased from GeneCopoeia, Inc. (Rockville, MD, USA). With the assistance of Polybrene (5 $\mu \mathrm{g} / \mathrm{ml}$; GeneCopoeia, Inc.), HCT-116 and Caco2 cells were transfected with Lv-LDOC1 or Lv-NC vectors, according to the manufacturer's protocol. Puromycin resistance markers were included in the vector; therefore, stable cell lines were selected by adding $1 \mu \mathrm{g} / \mathrm{ml}$ puromycin (Sigma-Aldrich;
Merck Millipore, Darmstadt, Germany) to the cell culture medium at $37^{\circ} \mathrm{C}$ for $3-5$ days after $48 \mathrm{~h}$ of transfection.

Reverse transcription-polymerase chain reaction (RT-PCR) and $R T-q P C R$. Total RNA was extracted from fresh CRC tissue samples and CRC cells with TRIzol ${ }^{\circledR}$ reagent (Takara Biotechnology Co., Ltd., Dalian, China), according to the manufacturer's protocols. For RT-PCR, RNA was reverse-transcribed into cDNA using PrimeScript ${ }^{\mathrm{TM}} \mathrm{RT}$ reagent kit (Takara Biotechnology Co., Ltd.). RT-PCR primers were purchased from Takara Biotechnology Co., Ltd., and the sequences were as follows: LDOC1, forward, 5'-CTATGCTGCCACTTCACA TCC-3' and reverse, 5'-GTGAGCTGTCCAAATCAATGTC-3' (126 bp); and $\beta$-actin, forward, 5'-ACTCTTCCAGCCTTCCTT CCT-3' and reverse, 5'-ACTCGTCATACTCCTGCTTGCT-3' (314 bp). RT-PCR was performed with Ex Taq ${ }^{\circledR}$ DNA polymerase (Takara Biotechnology Co., Ltd.) under the following thermal conditions: $95^{\circ} \mathrm{C}$ for $2 \mathrm{~min}, 95^{\circ} \mathrm{C}$ for $30 \mathrm{sec}, 55^{\circ} \mathrm{C}$ for $30 \mathrm{sec}, 72^{\circ} \mathrm{C}$ for $30 \mathrm{sec}$ and a final extension at $72^{\circ} \mathrm{C}$ for $3 \mathrm{~min}$. The RT-PCR duration for LDOC1 was 33 cycles, and for $\beta$-actin it was 23 cycles. The products of RT-PCR were electrophoresed in $2 \%$ agarose gels, and subjected to densitometric analysis with a gel imaging system (Quantity One 1-D Analysis Software version 4.6.2; Bio-Rad Laboratories, Inc., Hercules, CA, USA). For RT-qPCR, total RNA was used for first-strand cDNA synthesis using a PrimeScript ${ }^{\mathrm{TM}}$ RT reagent kit with gDNA Eraser (Takara Biotechnology Co., Ltd.). Primers were designed by Genscript (Nanjing, China), and the sequences were as follows: LDOC1, forward, 5'-GCATTCCTAATCAGCCTCC TCA-3' and reverse, 5'-CAAAGCACTGTTTCATCTCATCG-3' (121 bp); and $\beta$-actin, forward, 5'-CCACGAAACTACCTTC AACTCC-3' and reverse, 5'-GTGATCTCCTTCTGCATCC TGT-3' (132 bp). qPCR was performed with TB Green ${ }^{\mathrm{TM}}$ Premix Ex Taq (Takara Biotechnology Co., Ltd.) in triplicate. The amplification conditions were as follows: $95^{\circ} \mathrm{C}$ for $30 \mathrm{sec}$, followed by 40 cycles of $95^{\circ} \mathrm{C}$ for $5 \mathrm{sec}$ and $60^{\circ} \mathrm{C}$ for $1 \mathrm{~min}$. All samples were run in triplicate. The relative expression levels of LDOC1 were measured using the $2^{-\Delta \Delta \mathrm{Cq}}$ method (25).

Cell proliferation assay. Cell Counting Kit-8 (cat. no. E1CK-000208-5; EnoGene Biotechnology, Nanjing, China) was used to detect cell proliferation. The stably transfected cell lines (HCT-116-LDOC1, HCT-116-NC, Caco2-LDOC1 and Caco2-NC) were seeded in 96-well plates at a density of 3,500 cells/well. CCK8 reagent was added into the wells, and cell proliferation was evaluated at $0,24,48$ and $72 \mathrm{~h}$ by measuring the $450 \mathrm{~nm}$ absorbance with a microplate reader (Bio-Rad Laboratories, Inc.).

Colony formation assay. The stably transfected cell lines were seeded in 6-well plates at a density of 500 cells/well for 2 weeks at $37^{\circ} \mathrm{C}$, and RPMI-1640 supplemented with $10 \%$ fetal bovine serum was replaced every 3 days. At room temperature, the clones were fixed with $4 \%$ paraformaldehyde for $15 \mathrm{~min}$ and stained with $0.1 \%$ crystal violet for $15 \mathrm{~min}$. The numbers of clones (>50 cells per colony) were counted under a fluorescent microscope (x200 magnification, Leica Microsystems GmbH, Wetzlar, Germany).

Cell cycle and apoptosis assays. For the cell cycle assay, HCT-116 and $\mathrm{Caco} 2$ cells were transfected for $48 \mathrm{~h}$ and then digested 
Table I. Clinicopathological features of the study cohort used for quantitative PCR.

\begin{tabular}{lc}
\hline Characteristics & Number \\
\hline Number of patients & 14 \\
Age (mean \pm SD), years & $61.36 \pm 10.60$ \\
Sex (male/female) & $8 / 6$ \\
Cancer types (colon cancer/rectal cancer) & $12 / 2$ \\
Lymph node metastasis (absent/present) & $9 / 5$ \\
Distant metastasis (absent/present) & $14 / 0$ \\
TNM stage (I/II/III/IV) & $1 / 8 / 5 / 0$ \\
\hline
\end{tabular}

a Staging system from the American Joint Committee on Cancer. $\mathrm{SD}$, standard deviation; TNM, tumor-node-metastasis.

with $0.25 \%$ EDTA-free trypsin. The cells were washed with pre-chilled PBS twice and fixed in 70\% pre-chilled ethanol for $48 \mathrm{~h}$ at $4^{\circ} \mathrm{C}$. RNase A $(10 \mathrm{mg} / \mathrm{ml}$; Sigma-Aldrich; Merck KGaA) was added to cells and incubated for $30 \mathrm{~min}$ at $37^{\circ} \mathrm{C}$ in an atmosphere containing $5 \% \mathrm{CO}_{2}$. Subsequently, the cells were stained with propidium iodide (PI; Beyotime Institute of Biotechnology, Shanghai, China) under the same conditions. The cell-cycle distributions were examined by a flow cytometer (BD Biosciences, Franklin Lakes, NJ, USA) and analyzed by FlowJo version 7.6 software (FlowJo LLC, Ashland, OR, USA). For cell apoptosis, the transfected cells (HCT-116 and Caco2) were also digested with $0.25 \%$ EDTA-free trypsin and suspended in PBS buffer. The cells were stained using an Annexin V-fluorescein isothiocyanate (FITC)/PI kit (BD Pharmingen; BD Biosciences) in the dark, and apoptosis was examined by a flow cytometer (BD Biosciences) and analyzed by FlowJo version 7.6 software (FlowJo LLC, Ashland, OR, USA).

Cell migration and invasion assays. Cell migration and invasion assays were detected using Transwell chambers (Corning Inc., Corning, NY, USA). For the migration assays, the stably transfected cell lines (HCT-116 and Caco2) were digested with trypsin and suspended $\left(2.5 \times 10^{5} \mathrm{cell} / \mathrm{s} / \mathrm{ml}\right)$ with RPMI-1640 medium. Cell suspension $(200 \mu \mathrm{l})$ was added to the upper chamber, and $700 \mu 1 \mathrm{RPMI}-1640$ medium containing $10 \%$ FBS was added to the lower chamber. After $46 \mathrm{~h}$, the migrated cells were fixed with $4 \%$ paraformaldehyde and stained with $0.1 \%$ crystal violet for $15 \mathrm{~min}$ each at room temperature. Subsequently, the cells from five random fields were counted under a microscope (x200 magnification; Leica Microsystems GmbH, Wetzlar, Germany). For the invasion assays, Matrigel (BD Biosciences) was diluted with RPMI-1640 medium at a 1:8 ratio. A $100 \mu \mathrm{l}$ aliquot of the mixture was added to the upper chamber and incubated at $37^{\circ} \mathrm{C}$ for $5 \mathrm{~h}$ to solidify. A $100 \mu 1$ RPMI-1640 aliquot containing $1 \times 10^{5}$ cells was added to the upper chamber; the subsequent steps were identical to the migration assay.

Immunohistochemical (IHC) staining. The colorectal cancer tissue samples $(\mathrm{n}=53)$ were fixed with $10 \%$ formalin at room temperature for $48 \mathrm{~h}$ and paraffin-embedded to make paraffin sections with thickness of $5 \mu \mathrm{m}$. The paraffin sections were
Table II. Clinicopathological features of the study cohort used for immunohistochemistry analysis.

\begin{tabular}{lc}
\hline Characteristics & Number \\
\hline Number of patients & 53 \\
Age (mean \pm SD), years & $63.68 \pm 13.96$ \\
Sex (male/female) & $31 / 22$ \\
Cancers types (colon cancer) & 53 \\
Tumor size (T1/T2) & $15 / 38$ \\
Lymph node metastasis & $28 / 25$ \\
Distant metastasis & $41 / 12$ \\
TNM stage (I/II/III/IV) & $13 / 15 / 13 / 12$
\end{tabular}

aStaging system from the American Joint Committee on Cancer. $\mathrm{T} 1, \leq 3 \mathrm{~cm} ; \mathrm{T} 2,>3 \mathrm{~cm}$; SD, standard deviation; TNM, tumor-nodemetastasis.

incubated at $60^{\circ} \mathrm{C}$ for $2 \mathrm{~h}$, successively placed into xylene and graded ethanol (100\% ethanol for $5 \mathrm{~min}, 95 \%$ ethanol for $5 \mathrm{~min}$ and $70 \%$ ethanol for $5 \mathrm{~min}$ ) for dewaxing and hydration, and then washed with PBS thrice. For antigen repair, the sections were placed into citric acid buffer $(10 \mathrm{mmol} / \mathrm{l}$, pH6.0; Sigma-Aldrich; Merck KGaA) for $25 \mathrm{~min}$ at $95^{\circ} \mathrm{C}$, and then cooled to room temperature and washed with PBS thrice. Subsequently, the sections were incubated with $3 \%$ hydrogen peroxide (cat. no. SP-0023; Beijing Biosynthesis Biotechnology Co., Ltd., Beijing, China) for $20 \mathrm{~min}$ at room temperature, followed by three washes with PBS. These sections were blocked by incubating with 5\% goat serum (cat. no. SP-0023; Beijing Biosynthesis Biotechnology Co., Ltd.) for $20 \mathrm{~min}$ at room temperature, and incubated with a rabbit polyclonal antibody (cat. no. bs-6543R; anti-LDOC1 antibody; 1:200 dilution; Beijing Biosynthesis Biotechnology Co., Ltd.) at $4^{\circ} \mathrm{C}$ overnight. Subsequently, the sections were washed with PBS thrice and horseradish peroxidase-conjugated goat anti-rabbit $\operatorname{IgG}$ (cat. no. SP-0023; 1:500 dilution; Beijing Biosynthesis Biotechnology Co., Ltd.) was added as a secondary antibody and incubated at room temperature for $20 \mathrm{~min}$. The slices were stained with diaminobenzidine (DAB kit; OriGene Technologies, Inc., Beijing, China) at room temperature for $2 \mathrm{~min}$. The nuclei were counterstained with hematoxylin at room temperature for $1 \mathrm{~min}$ and washed immediately with tap water for $10 \mathrm{~min}$. The slices were successively placed into graded ethanol (70\% ethanol for $5 \mathrm{~min}$, 95\% ethanol for $5 \mathrm{~min}$ and $100 \%$ ethanol for $5 \mathrm{~min}$ ) and xylene for dehydration and sealed with neutral gum pieces. Image was captured using a Leica microscope image system (x100 and x400 magnification; Leica Microsystems GmbH, Wetzlar, Germany). IHC scores were determined according to the intensity of immunostaining ( 0 , no staining reaction; 1 , mild reaction; 2 , moderate reaction; and 3 , intense reaction) and the percentage of positive cells $(0$, no positive cells; $1, \leq 10 \%$ positive cells; $2,11-50 \%$ positive cells; $3,51-80 \%$ positive cells; and $4,>80 \%$ positive cells). An overall score was derived by multiplying the intensity and percentage scores (26).

Immunofluorescence assay. The HCT-116 and Caco2 cells were transfected for $48 \mathrm{~h}$ and seeded in 24-well plates with 
glass coverslips at $37^{\circ} \mathrm{C}$ overnight. The cells were fixed with $4 \%$ paraformaldehyde for $20 \mathrm{~min}$ at room temperature and washed with PBS thrice. The samples were soaked in 0.5\% Triton X-100 (Beyotime Institute of Biotechnology) at room temperature for $20 \mathrm{~min}$. Subsequently, the cells were blocked with $1 \%$ bovine serum albumin (Beyotime Institute of Biotechnology) at room temperature for $1 \mathrm{~h}$ and incubated with primary antibody (cat. no. 8480 ; anti- $\beta$-catenin antibody; 1:100 dilution; Cell Signaling Technology, Inc., Danvers, MA, USA) at $4^{\circ} \mathrm{C}$ overnight. Subsequently, the samples were incubated with Alexa Fluor ${ }^{\circledR} 555$-conjugated (cat. no. 4413; 1:500 dilution; Cell Signaling Technology, Inc.) secondary antibody against rabbit IgG for $1 \mathrm{~h}$ in the dark at $37^{\circ} \mathrm{C}$, and washed with PBS thrice. The cell nuclei were stained with DAPI (Sigma-Aldrich; Merck KGaA) at room temperature for $5 \mathrm{~min}$ in the dark. The samples were sealed with the sealing liquid, and then the images were observed under a fluorescence microscope (x400 magnification; Leica Microsystems GmbH).

Western blotting. Proteins were extracted from $\mathrm{Caco} 2$ and HCT-116 cells at $48 \mathrm{~h}$ post-transfection using radioimmunoprecipitation assay lysis buffer and phenylmethanesulfonyl fluoride (both from Beyotime Institute of Biotechnology). These protein concentrations were quantified with a Bicinchoninic Acid kit (Beyotime Institute of Biotechnology). Total proteins $(20-40 \mathrm{mg}$ ) were separated by $10 \%$ SDS-PAGE and then transferred onto polyvinylidene fluoride membranes. The membrane was blocked in 5\% skim milk at room temperature for 2-3 $\mathrm{h}$ and incubated with the primary antibodies at $4^{\circ} \mathrm{C}$ overnight. Subsequently, the membrane was washed with PBS thrice and incubated with horseradish peroxidase-conjugated goat anti-rabbit IgG (cat. no. bs-0295G-HRP; 1:5,000 dilution; Beijing Biosynthesis Biotechnology Co., Ltd.) at room temperature for 1-2 h. Chemiluminescent reagents (BeyoECL Moon; Beyotime Institute of Biotechnology) were used to detect protein levels. Western blot bands were analyzed with ImageJ software (version 6.0; National Institutes of Health, Bethesda, MD, USA). The primary antibodies used included: Rabbit anti-p65 (cat. no. 8242; 1:1,000), anti-phospho-IкB $\alpha$ (cat. no. 2859; 1:1,000), anti-B-cell lymphoma-2 (Bcl-2)-associated X (Bax; cat. no. 5023; 1:1,000), anti-Bcl-2 (cat. no. 3498; 1:1,000), anti-E-cadherin (cat. no. $3195 ; 1: 1,000$ ), anti-N-cadherin (cat. no. 13116; $1: 1,000$ ), anti-vimentin (cat. no. 5741; 1:1,000), anti- $\beta$-catenin (cat. no. 8480; 1:1,000), anti-glycogen synthase kinase-3 $\beta$ (GSK-3 $\beta$; cat. no. 9315; 1:1,000) and anti-c-myc (cat. no. 5605; 1:1,000) from Cell Signaling Technology, Inc.; anti-cleaved caspase-3 (cat. no. WL01992; 1:500), anti-Bcl-extra large (Bcl-xl; cat. no. WL01558; 1:500) and anti-matrix metallopeptidase 2 (MMP2; cat. no. WL1579; 1:300) from Wanleibio Co., Ltd. (Shanghai, China); and anti-GAPDH (cat. no. bs-2188R; 1:5,000) from Beijing Biosynthesis Biotechnology Co., Ltd.

Statistical analysis. Statistical analyses were performed with GraphPad Prism software version 5.0 (GraphPad Software,Inc., La Jolla, CA, USA). Data are presented as the mean \pm standard deviation. The differences between two groups were analyzed using Student's t-test. Any statistical differences between three groups were evaluated using a one-way of variance with
Dunnett's multiple comparison post-hoc tests. $\mathrm{P}<0.05$ was considered to indicate a statistically significant difference.

\section{Results}

Expression of LDOC1 in CRC tissues and cell lines. mRNA and protein expression levels of LDOC1 in CRC and normal colorectal tissues were detected by RT-qPCR and IHC. mRNA levels of LDOC1 in 14 CRC tissues were significantly downregulated, compared with the levels in paired normal colorectal tissues $(\mathrm{P}<0.05$; Fig. $1 \mathrm{~A})$. The IHC results demonstrated that protein expression levels of LDOC1 in CRC tissues $(n=53)$ were significantly decreased, compared with normal tissues ( $\mathrm{n}=18 ; \mathrm{P}<0.0001 ;$ Fig. 1B). Furthermore, the expression levels of LDOC1 in four CRC cell lines were measured by RT-PCR analysis. LDOC1 expression was notably repressed in the four CRC cell lines, compared with normal colorectal tissues, particularly in HCT-116 and Caco2 cells (Fig. 1C). Therefore, these two cell lines were selected for subsequent experiments.

Verification of the LDCO1 overexpression following transfection. HCT-116 and Caco2 cells were transfected with Lv-LDOC1 or Lv-NC. The mRNA and protein levels of LDOC1 were detected by RT-PCR and western blot analysis in the HTC-116 and Caco2 cell lines. The results demonstrated that the mRNA and protein expression levels were significantly upregulated in the HCT-116 (Lv-LDOC1; P $<0.01)$ and Caco2 $(\mathrm{Lv}-\mathrm{LDOC1}$; $\mathrm{P}<0.05)$ cell lines (Fig. 1D and E).

LDOCl inhibits CRC cell proliferation and colony formation. CCK8 and colony formation experiments were used to examine the effect of $\mathrm{LDOC1}$ on the proliferation capacity of CRC cells. The CCK8 results demonstrated that LDOC1 overexpression significantly inhibits the proliferation of CRC cells (HTC-116 and Caco2), compared with the negative control at 24, 28 and $72 \mathrm{~h}(\mathrm{P}<0.01$; Fig. 2A). Additionally, the colony formation assay demonstrated that Lv-LDOC1 cells formed significantly reduced colonies, compared with Lv-NC cells $(\mathrm{P}<0.01$; Fig. 2B). However, the aforementioned results indicated that the effect of LDOC1 on $\mathrm{Caco} 2$ cells in the colony formation experiment is not as notable as that in the CCK8 experiment. It is probable that the period of the CCK8 experiment is significantly shorter, compared with the colony formation experiment. In the early stage, LDOC1 strongly inhibited the proliferation of $\mathrm{Caco} 2$ cells, while in the later stage, $\mathrm{Caco} 2$ cells grew relatively faster, compared with the earlier stage, due to LDOC1 having a weak effect on promoting apoptosis and cycle arrest. However, these results demonstrated that $\mathrm{LDOC} 1$ could suppress the proliferation of CRC cells.

LDOCl induces cell-cycle arrest and apoptosis in CRC cells. The effects of LDOC1 on cell cycle and apoptosis of CRC cells were measured by flow cytometry. The results demonstrated that the HCT116 (Lv-LDOC1) cells were significantly arrested in the $\mathrm{G} 0 / \mathrm{G} 1$ phase $(\mathrm{P}<0.0001)$, and Caco2 (Lv-LDCO1) cells were significantly arrested in the $\mathrm{G} 2 / \mathrm{M}$ phase $(\mathrm{P}<0.001)$ (Fig. 3A). The aforementioned results may be due to LDOC1 regulating the expression of cyclin D1, 
A
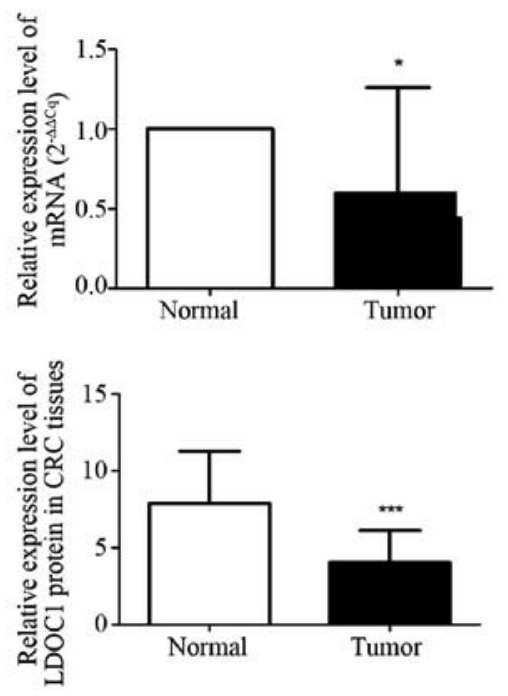

C

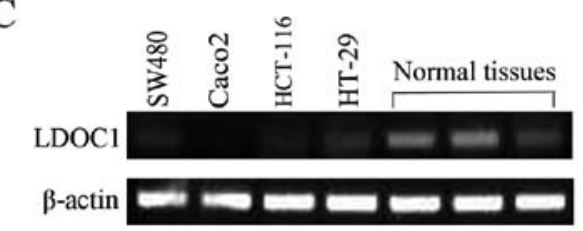

D

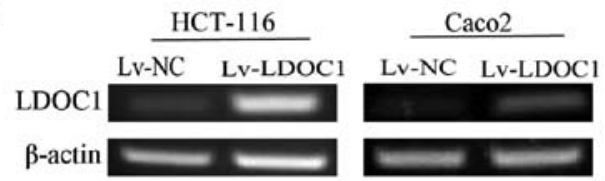

E

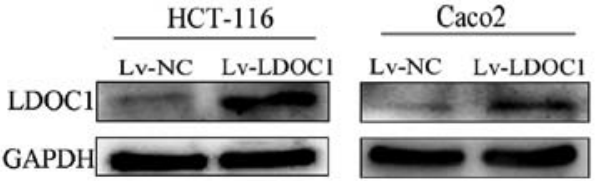

B
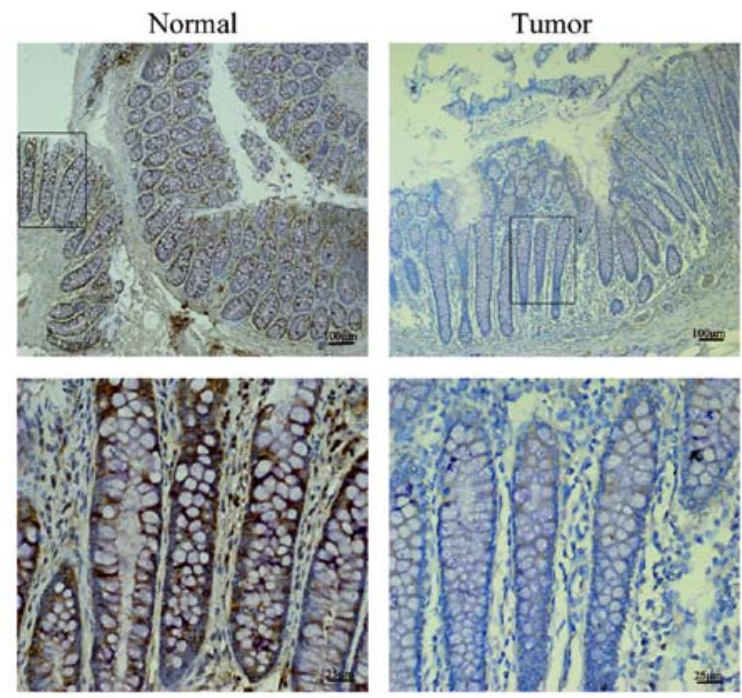

Caco2
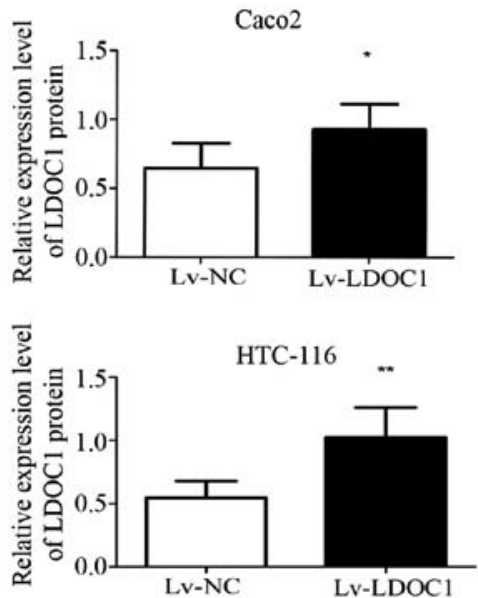

Figure 1. Expression of LDOC1 in colorectal cancer tissues, cell lines, and Caco2 and HCT-116 cells transfected with lentiviral expression vector. (A) mRNA expression level of LDOC1 in 14 paired CRC tissues and normal adjacent tissues was detected by reverse transcription-quantitative polymerase chain reaction with $\beta$-actin as a control. According to the quantitative analysis, LDOC1 was expressed at significantly reduced levels in CRC tissues, compared with normal adjacent tissues. (B) Representative images of immunohistochemical staining for LDOC1 protein in normal colorectal tissues and colorectal cancer tissues (x100 and x400). LDOC1 was decreased significantly in CRC tissues, compared with normal adjacent tissues. (C) RT-PCR was used to detect mRNA expression of LDOC1 in four colorectal cancer cell lines and normal colorectal tissues. LDOC1 expression level was significantly reduced in four CRC cell lines, compared with normal colorectal tissues. (D) mRNA expression level of LDOC1 in the transfected cells was detected by RT-PCR, LDOC1 was notably increased in Lv-LDOC1, compared with Lv-NC. (E) Protein expression level of LDOC1 in the transfected cells was detected by western blot analysis, LDOC1 was notably increased in Lv-LDOC1, compared with Lv-NC. ${ }^{*} \mathrm{P}<0.05,{ }^{* *} \mathrm{P}<0.01$ and ${ }^{* * *} \mathrm{P}<0.001$. LDOC1, leucine zipper downregulated in cancer 1 ; CRC, colorectal cancer; RT-PCR, reverse transcription-polymerase chain reaction; Lv-LDOC1, LDOC1-overexpressing cells; Lv-NC, negative control cells.

cyclin E and cyclin dependent kinase 2 (CDK2) in HCT-116 cells, resulting in G0/G1 phase block, while LDOC1 regulates the expression of cyclin $\mathrm{B}$ and $\mathrm{CDK} 1$ in $\mathrm{Caco} 2$ cells, resulting in G2/M phase block $(27,28)$. Annexin V-FITC/PI staining demonstrated that the rate of apoptosis of the HTC116 (Lv-LDCO1; $\mathrm{P}<0.0001)$ and Caco2 (Lv-LDCO1; $\mathrm{P}<0.0001)$ cells were significantly increased, compared with the empty lentiviral vector cells (Fig. 3B). Additionally, LDOC1 has been indicated to regulate the NF- $\mathrm{KB}$ signaling pathway, thereby affecting apoptosis of cancer cells in a number of cancer types, including papillary thyroid carcinoma, cervical cancer and pancreatic cancer $(6,12,13)$. Therefore, the critical factors of the NF- $\mathrm{KB}$ signaling pathway and apoptosis-associated factors were detected by western blot analysis. As depicted in Fig. 3, expression of the apoptosis-associated factors cleaved caspase-3 and Bax increased, whereas expression of $\mathrm{Bcl}-2$ and $\mathrm{Bcl}-\mathrm{xl}$, as well as the critical factors of NF- $\mathrm{KB}$ signaling pathway, including p65 and p-IкB $\alpha$, decreased in Lv-LDOC1 cells, compared with the expression in Lv-NC cells (Fig. 3C). These results indicated that LDOC1 arrests cell cycle and promotes apoptosis.

LDOC1 inhibits CRC cell migration and invasion. To investigate the effect of LDOC1 on migration and invasion of colon cancer cells, Transwell and Matrigel assays were conducted. According to the Transwell and Matrigel assay results, the number of migrating and invasive cells in the LDOC1 overexpression group was significantly reduced, compared with the control group $(\mathrm{P}<0.01$; Fig. $4 \mathrm{~A}$ and $\mathrm{B})$. Therefore, $\mathrm{LDOC1}$ inhibits the migration and invasion of CRC cells. 
A

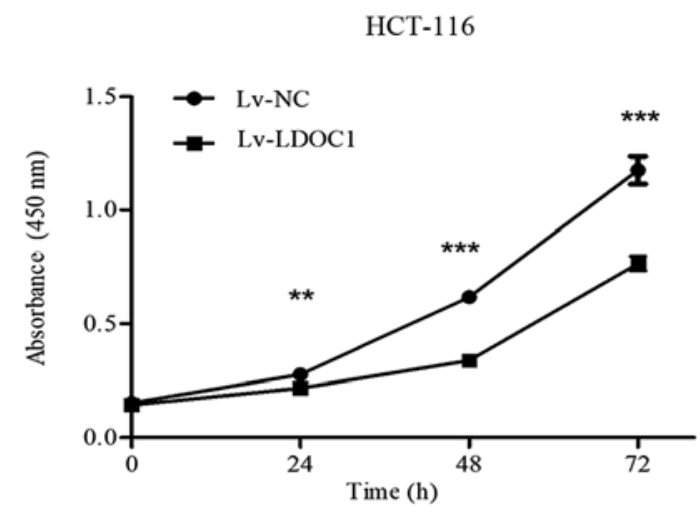

B

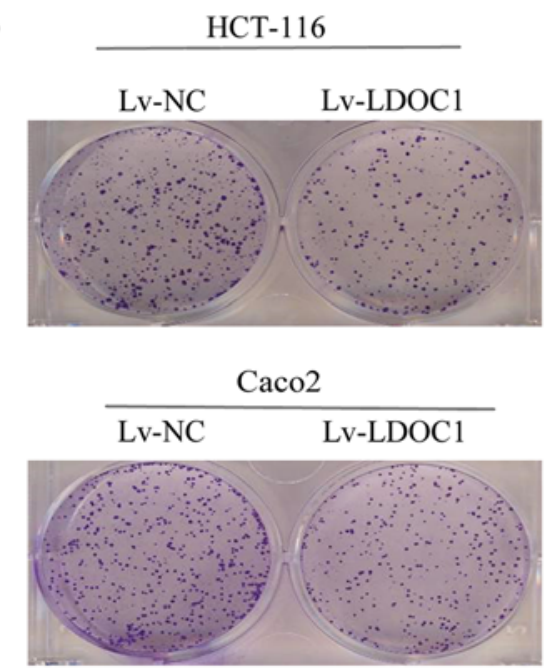

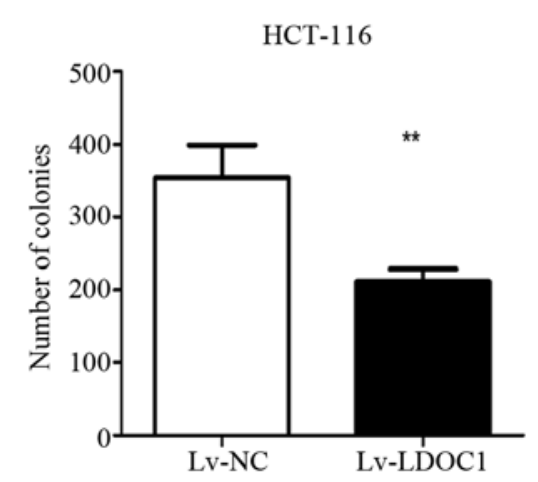

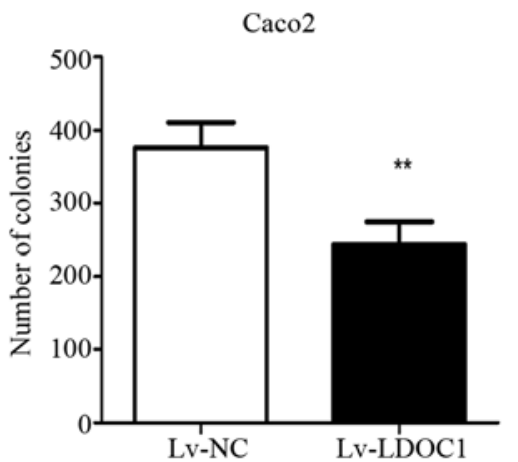

Figure 2. Cell Counting Kit-8 and colony formation assays to detect cell proliferation. (A) The proliferation rate of Lv-LDOC1 was inhibited, compared with Lv-NC. (B) LDOC1 overexpression inhibited the formation of HCT-116 and Caco2 cells colonies. ${ }^{* *} \mathrm{P}<0.01$ and ${ }^{* * *} \mathrm{P}<0.001$ vs. Lv-NC. LDOC1, leucine zipper downregulated in cancer 1; Lv-LDOC1, LDOC1-overexpressing cells; Lv-NC, negative control cells.

LDOC1 inhibits migration, invasion and EMT by downregulation of the Wnt/ $\beta$-catenin pathway in CRC cells. The $\mathrm{Wnt} / \beta$-catenin signaling pathway serves a crucial role in the development of numerous cancer types, including cervical, ovarian and lung cancer, particularly in invasion, migration and EMT (19-21). Therefore, western blot analysis was used to investigate whether overexpression of LDOC1 had any effect on the Wnt/ $\beta$-catenin pathway, migration, invasion and EMT. As the results demonstrated, the levels of the core protein $\beta$-catenin and the downstream target gene $\mathrm{c}$-myc of the Wnt/ $\beta$-catenin pathway were decreased in LDOC1-overexpressing CRC cells, compared with their expression in control CRC cells. However, expression of GSK-3 $\beta$, a critical upstream enzyme of the Wnt/ $\beta$-catenin pathway, was increased in LDOC1-overexpressing cells, compared with the NC cells. Furthermore, the levels of EMT-associated proteins, including $\mathrm{N}$-cadherin, vimentin and MMP2 were decreased, while E-cadherin levels were increased in LDOC1-overexpressing cells, compared with $\mathrm{NC}$ cells (Fig. 5A). According to the results of cellular immunofluorescence, LDOC1-overexpressing cells reduced the levels of total $\beta$-catenin and nuclear $\beta$-catenin, compared with NC cells $(\mathrm{P}<0.05$; Fig. 5B).

To further verify whether LDOC1 inhibits CRC cell migration and invasion by regulating the $\mathrm{Wnt} / \beta$-catenin pathway, the Wnt/ $\beta$-catenin pathway activator IM-12 was used. IM-12 has been demonstrated to inhibit the expression level of GSK-3 $\beta$, thereby reducing phosphorylation of $\beta$-catenin and promoting the expression of $\beta$-catenin as a core protein of the $\mathrm{Wnt} / \beta$-catenin pathway $(29,30)$. Protein expression in Lv-NC cells, Lv-NC cells treated with IM-12 (Lv-NC+IM-12 group) and Lv-LDOC1 cells treated with IM-12 (Lv-LDOC1+IM-12 group), was evaluated with a western blot assay. The western blot assay results demonstrated that GSK-3 $\beta$ was notably decreased, and $\beta$-catenin, MMP2, and N-cadherin were notably increased in Lv-NC cells treated with IM-12, compared with their levels in Lv-NC cells. This indicates that the Wnt/ $\beta$-catenin pathway is activated, and promotes migration and invasion following IM-12 addition to CRC cells. It was also determined that GSK-3 $\beta$ was notably increased and $\beta$-catenin, MMP2, and N-cadherin were significantly decreased in Lv-LDOC1 cells treated with IM-12, compared with their levels in Lv-NC cells treated with IM-12 (Fig. 6). It was further verified that LDOC1 inhibited migration, invasion and EMT of CRC cells via downregulation of the $\mathrm{Wnt} / \beta$-catenin pathway.

\section{Discussion}

The occurrence and development of tumors result from interactions of biological and environmental factors (31). However, in terms of the molecular mechanism, the progression from 
A
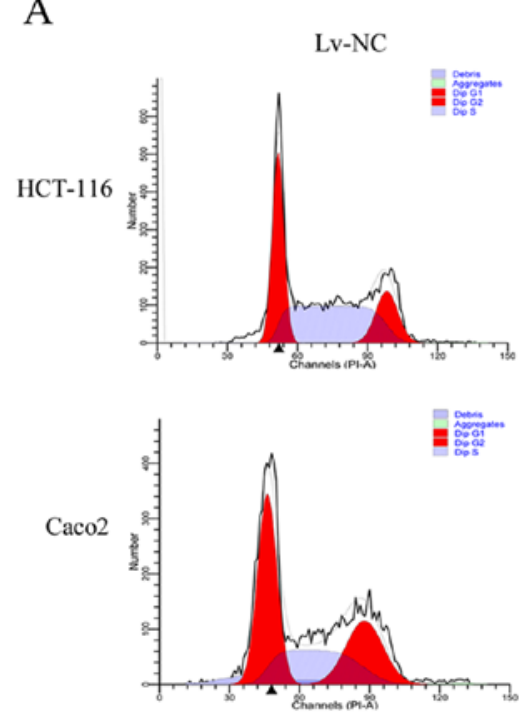

B
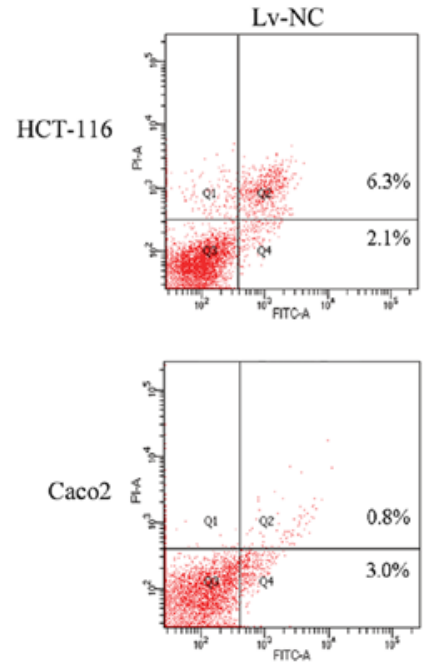

$\mathrm{C}$

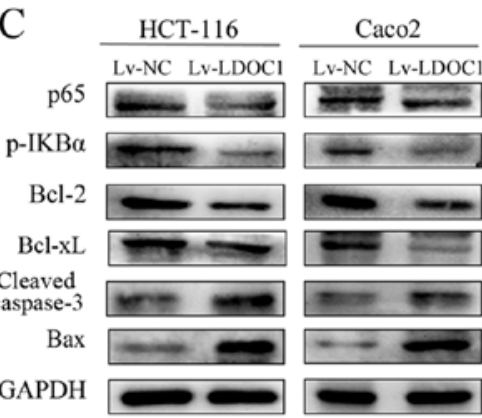

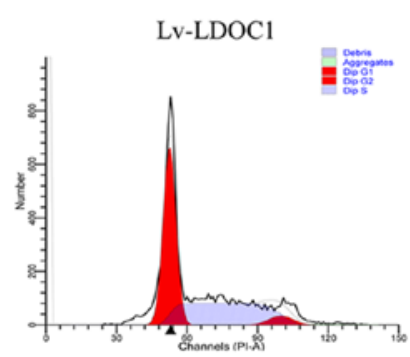
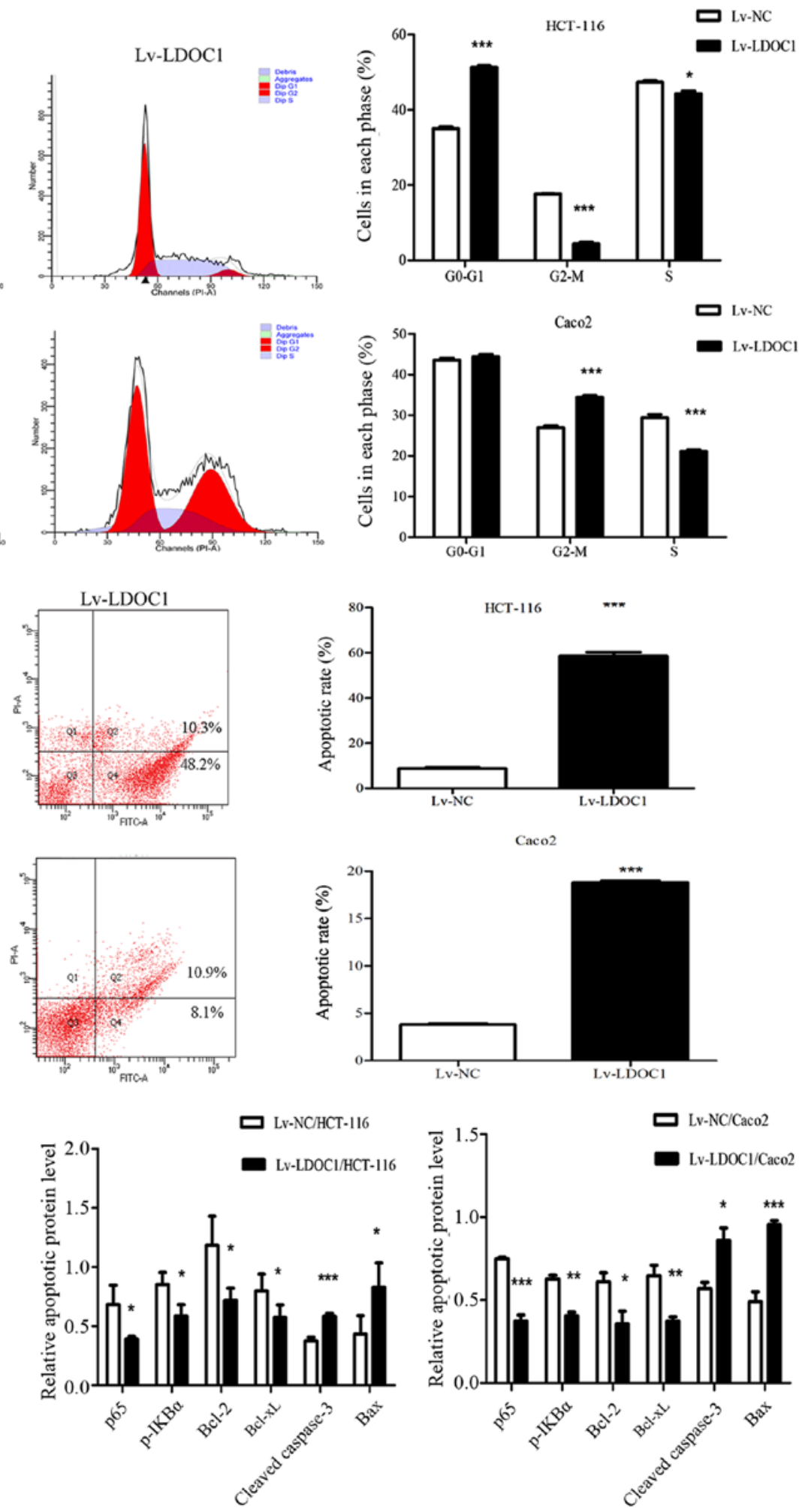

Figure 3. Apoptosis rate and cell cycle phase distribution in the transfected cells were detected by flow cytometry, and the expression of apoptosis-associated proteins was analyzed by western blotting. (A) From the cell-cycle distributions, HCT116 (Lv-LDOC1) cells were significantly arrested in the G0/G1 phase and $\mathrm{Caco} 2$ (Lv-LDOC1) cells were significantly arrested in the G2/M phase. (B) The apoptosis rates of Lv-LDOC1 were increased, compared with Lv-NC. (C) Lv-LDOC1 increased cleaved caspase-3 and Bax levels and reduced p65, p-IKB $\alpha, \mathrm{Bcl}-2$ and Bcl-xl levels, compared with $\mathrm{Lv}-\mathrm{NC}$. ${ }^{*} \mathrm{P}<0.05$, "* $\mathrm{P}<0.01$ and ${ }^{* * *} \mathrm{P}<0.001$ vs. Lv-NC. Bcl-2, B-cell lymphoma-2; Bcl-xl, B-cell lymphoma extra-large; Bax, Bcl-2-associated X protein; $\mathrm{p}$-IKB $\alpha$ : phosphorylated inhibitor$\kappa-\mathrm{B} \alpha ; \mathrm{Lv}-\mathrm{LDOC1}, \mathrm{LDOC1}$-overexpressing cells; Lv-NC, negative control cells.

normal to cancer cell is the result of gene mutation, which includes activation of pro-oncogenes and inactivation of tumor suppressor genes (4). Therefore, the identification of novel tumor markers, their biological functions and molecular mechanisms in CRC may contribute to the diagnosis, treatment and prognosis of CRC.

The decreased expression of LDOC1 has been observed in certain malignancy types, including papillary thyroid 

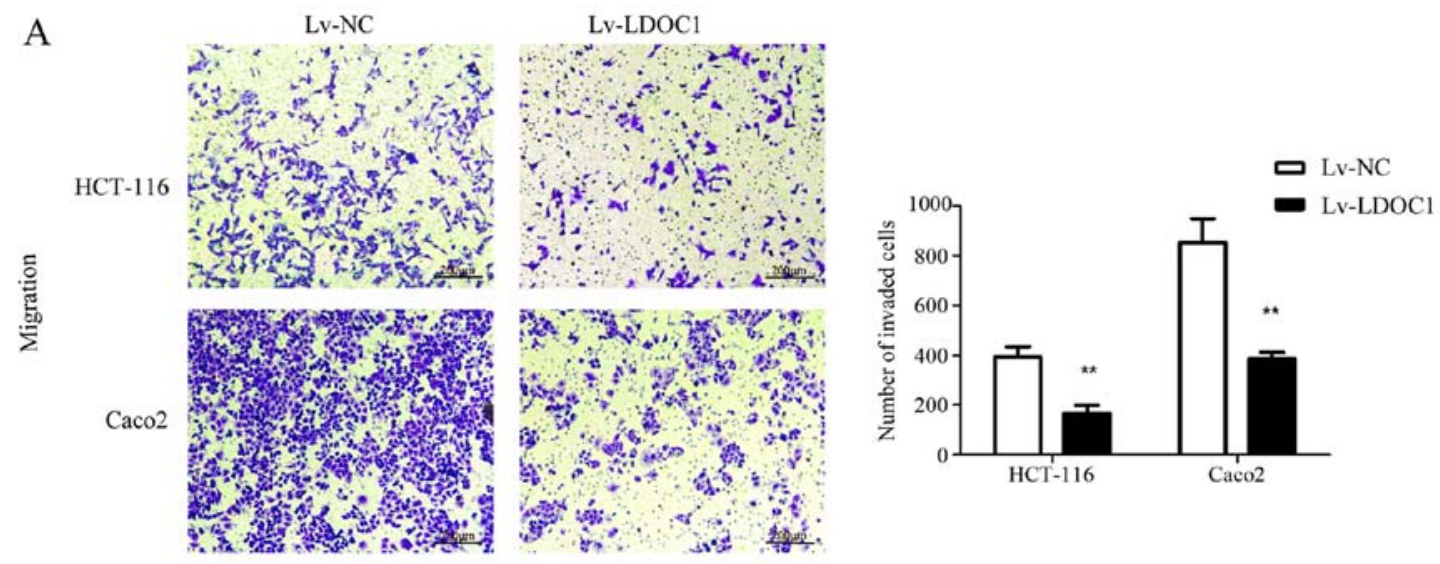

B
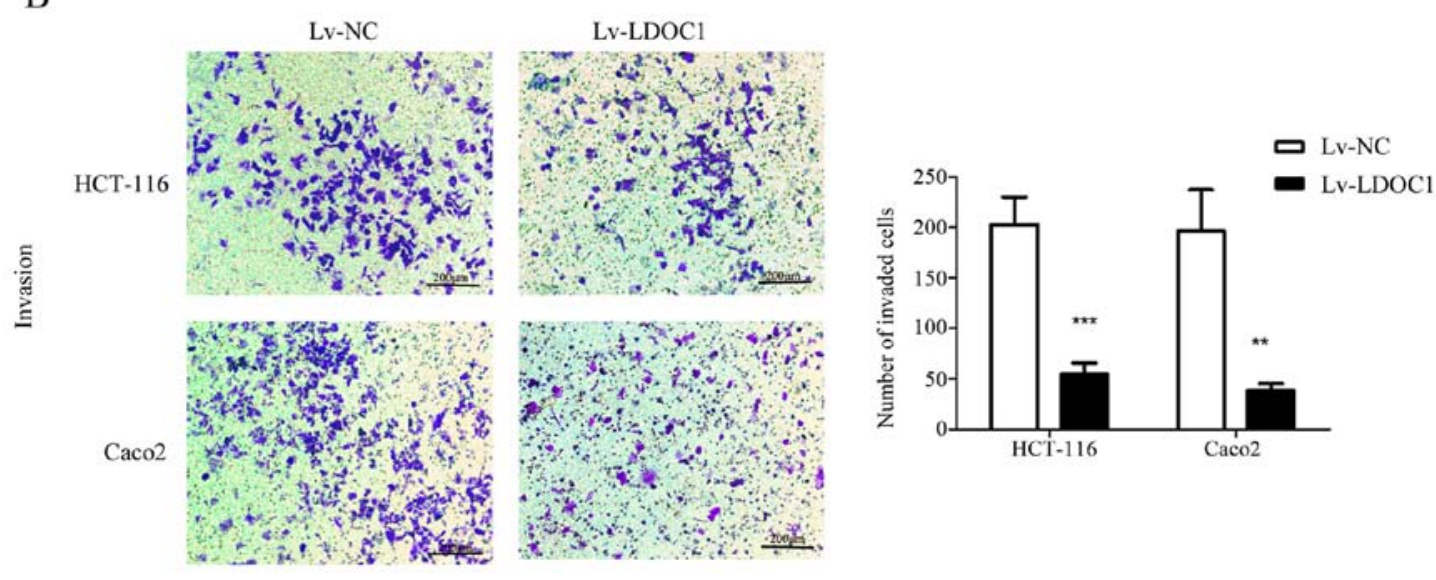

Figure 4. Motility of transfected cells was detected by Transwell assays. Following LDOC1 overexpression (Lv-LDOC1), the (A) migration and (B) invasion capacity of HCT-116 and Caco2 cells were decreased, compared with Lv-NC (x200). ${ }^{* *} \mathrm{P}<0.01$ and ${ }^{* * * *} \mathrm{P}<0.001$ vs. Lv-NC. LDOC1, leucine zipper downregulated in cancer 1; Lv-LDOC1, LDOC1-overexpressing cells; Lv-NC, negative control cells.

carcinoma, liver cancer and prostate cancer (6-11). Studies demonstrated that LDOC1 inhibits cell proliferation and promotes apoptosis via downregulation of the NF- $\mathrm{kB}$ signaling pathway in a number of cancer types, papillary thyroid carcinoma, cervical cancer and pancreatic cancer (6,12-13). However, the effect of LDOC1 expression on the migration and invasion of cancer cells is rarely reported. In the present study, using RT-qPCR, IHC and RT-PCR, it was determined, for the first time, that LDOC1 expression is decreased in CRC tissues and cells. Subsequently, it was indicated that LDOC1 overexpression inhibits cell proliferation and cell cycle arrest, and promotes cell apoptosis. Subsequently, the associated proteins were examined and it was determined that the expression levels of $\mathrm{p} 65$, phosphorylated inhibitor- $\mathrm{k}-\mathrm{B} \alpha(\mathrm{p}-\mathrm{IKB} \alpha), \mathrm{Bcl}-2$ and $\mathrm{Bcl}-\mathrm{xl}$ are decreased, while expression levels of cleaved caspase- 3 and Bax are increased. In the NF- $\kappa B$ signaling pathway, p50/p65 binds to I $\mathrm{B} \alpha$ to form an inactive trimer. Following phosphorylation of $\mathrm{I} \kappa \mathrm{B} \alpha, \mathrm{p} 65$ activates and enters the nucleus to regulate the expression of apoptosis-associated target genes, including anti-apoptotic Bcl-2 family, pro-apoptotic Bax and apoptosis executioner caspase-3 (6,32-36). LDOC1 may promote apoptosis by inhibiting the NF- $\mathrm{KB}$ pathway in $\mathrm{CRC}$, but the regulatory mechanism involved requires further elaboration.

Additionally, LDOC1 overexpression inhibited migration and invasion of CRC cells, which was confirmed with Transwell and Matrigel assays. In osteosarcoma, LDOC1 has been demonstrated to inhibit cell metastasis by downregulating the Wnt5a pathway (16). However, there is an indirect association between the Wnt5a and Wnt/ $\beta$-catenin signaling pathways $(17,18)$. The $\mathrm{Wnt} / \beta$-catenin signaling pathway serves an important role in regulating cell metastasis and EMT of CRC (19-21). Therefore, the protein expression levels of the core factors of the Wnt/ $\beta$-catenin pathway and metastasis-associated genes were detected. Western blot analysis results indicated that LDOC1 overexpression reduced $\beta$-catenin and c-myc levels, and increased GSK-3 $\beta$ levels, compared with control cells. Immunofluorescence results also demonstrated that total and nuclear $\beta$-catenin has reduced levels in the LDOC1 overexpression group, compared with the control group. Particularly in HCT-116 cells, the localization of $\beta$-catenin in the control group was notably changed from nucleus to cytoplasm following LDOC1 overexpression. As a core protein of the Wnt/ $\beta$-catenin signaling pathway, $\beta$-catenin accumulates in the cytoplasm and enters the nucleus when the pathway is activated, which promotes the transcription of multiple target genes and thus promotes proliferation and metastasis $(37,38)$. Therefore, $\beta$-catenin can indirectly promote cell metastasis, while reducing the expression of $\beta$-catenin in the nucleus can inhibit cell metastasis. Additionally, the E-cadherin expression increased, while MMP2, vimentin and $\mathrm{N}$-cadherin protein levels decreased in LDOC1-overexpressing cells, which were associated with EMT. In the process of EMT, E-cadherin is reduced as a marker of 
A

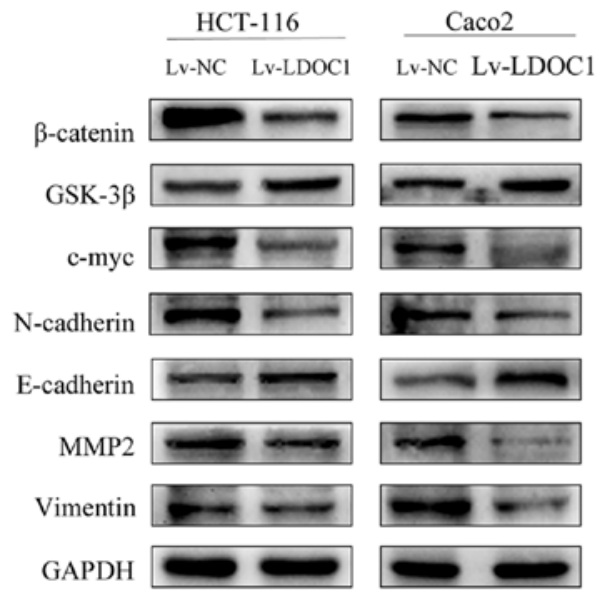

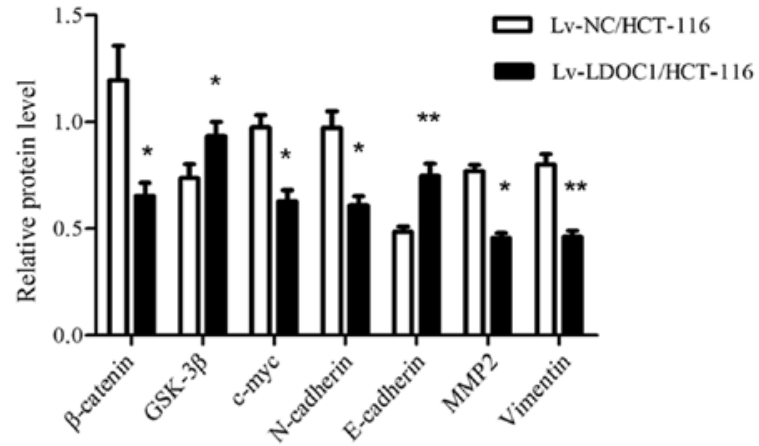

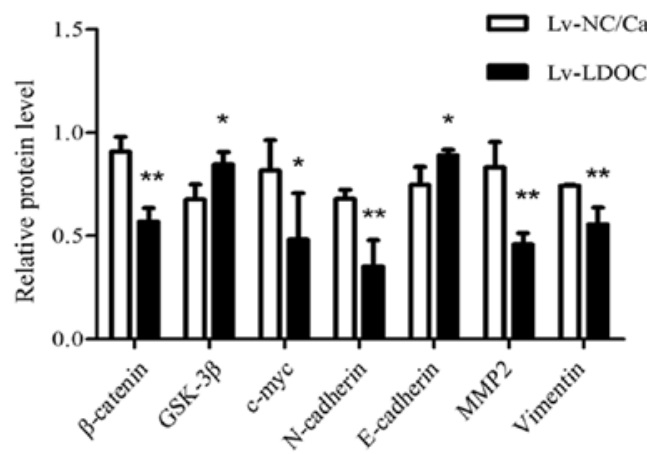

B

HCT-116

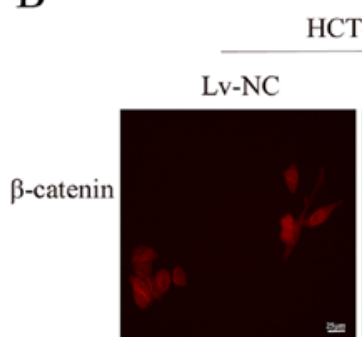

Lv-LDOC1
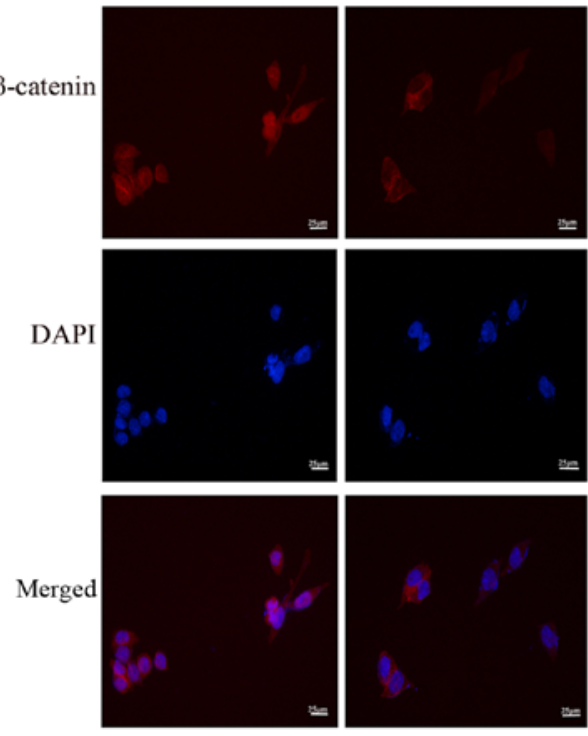

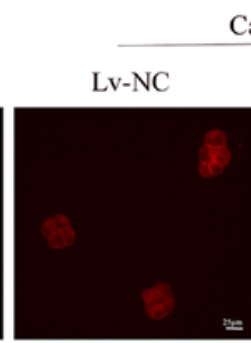

$\mathrm{Caco} 2$
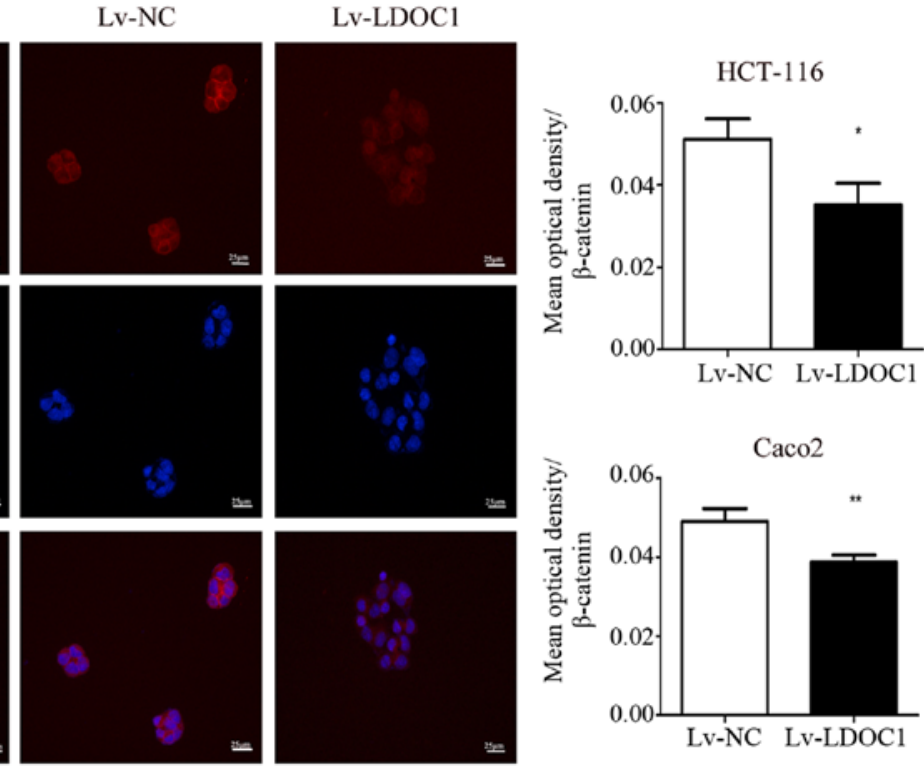

Figure 5. Effects of LDOC1 overexpression on proteins associated with the Wnt/ $/$-catenin signaling pathway, metastasis and epithelial-mesenchymal transition. (A) Western blot analysis demonstrated that Lv-LDOC1 increased GSK-3 $\beta$ and E-cadherin levels, and decreased $\beta$-catenin, c-myc, N-cadherin, MMP2 and vimentin levels in HCT-116 and Caco2 cells. (B) Immunofluorescence analysis for $\beta$-catenin in the transfected cells (x400). The $\beta$-catenin protein is labelled in red, and cell nuclei are labelled in blue by DAPI staining. Lv-LDOC1 decreased $\beta$-catenin levels, compared with Lv-NC in HCT-116 and Caco2 cells. ${ }^{*} \mathrm{P}<0.05$ and ${ }^{* *} \mathrm{P}<0.01$ vs. Lv-NC. LDOC1, leucine zipper downregulated in cancer 1; MMP2, matrix metalloproteinase 2; GSK-3 $\beta$, glycogen synthase kinase-3 $\beta$; Lv-LDOC1, LDOC1-overexpressing cells; Lv-NC, negative control cells.

epithelial cells, resulting in the loss of epithelial cell polarity and the reduction of intercellular adhesion (39). N-cadherin and vimentin increased as markers of mesenchymal cells, which, together with MMP2, enhance cell movement ability. This indicated that LDOC1 inhibited migration, invasion and EMT of colon cancer cells by downregulating the Wnt/ $\beta$-catenin signaling pathway. Furthermore, IM-12 was used to inhibit the expression of GSK-3 $\beta$ and reduce phosphorylation of $\beta$-catenin to activate the Wnt/ $\beta$-catenin signaling pathway. The western blot assay results demonstrated that GSK-3 $\beta$ level is notably increased, and $\beta$-catenin, MMP2 and $\mathrm{N}$-cadherin levels are significantly decreased in Lv-LDOC1 cells treated with IM-12, compared with the levels in Lv-NC cells treated with IM-12. It was further verified that LDOC1 inhibits metastasis of colon cancer cells by downregulating the Wnt $/ \beta$-catenin signaling pathway. However, it is notable that there are differences in cell 

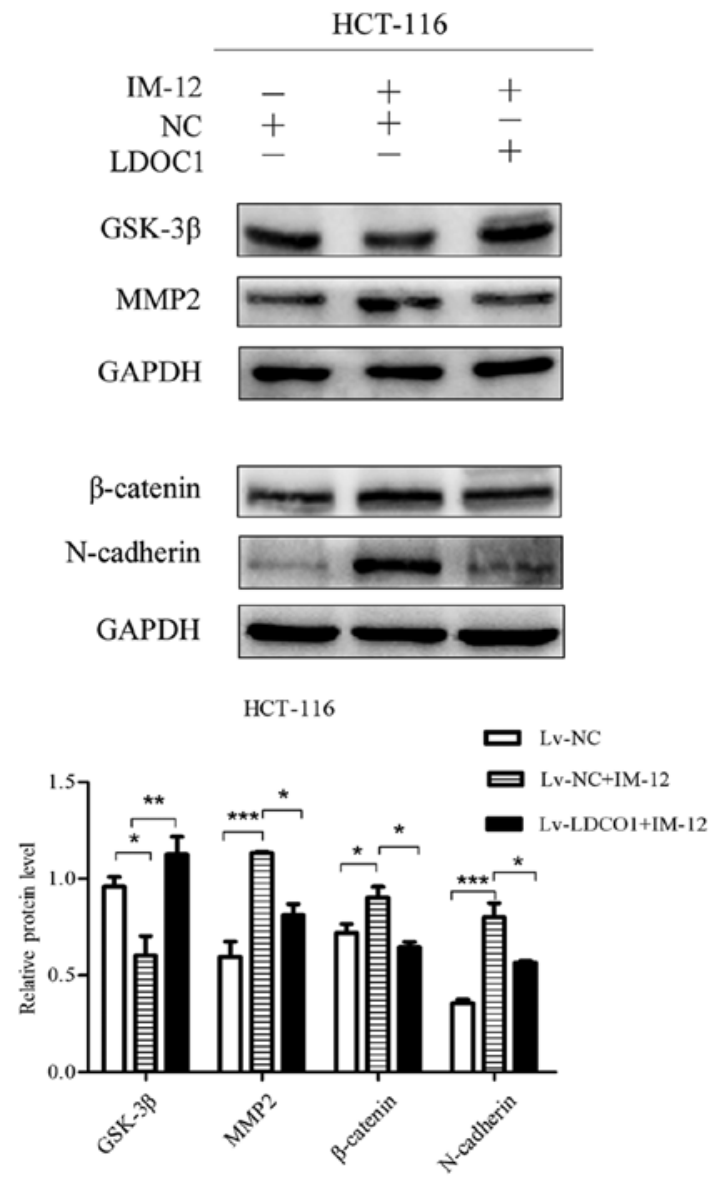
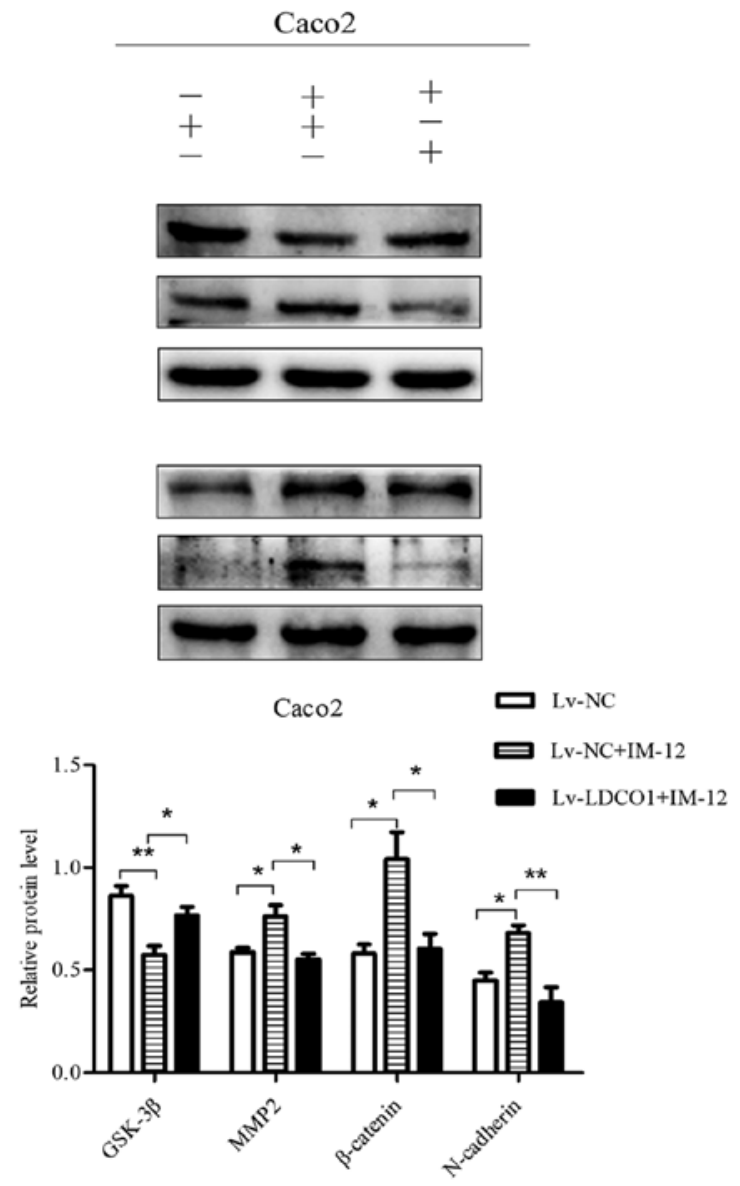

Figure 6. Effects of IM-12 and LDOC1 overexpression on proteins associated with the Wnt/ $\beta$-catenin signaling pathway and metastasis in colon cancer cells. Western blot analysis demonstrated that IM-12 decreased GSK-3 $\beta$ expression, and increased expression of $\beta$-catenin, MMP2 and N-cadherin in Lv-NC treated with IM-12, compared with their levels in Lv-NC. Lv-LDOC1 increased GSK-3 $\beta$ expression, and decreased expression of $\beta$-catenin, MMP2 and $\mathrm{N}$-cadherin in Lv-LDOC1 treated with IM-12, compared with the levels in Lv-NC treated with IM-12. ${ }^{*} \mathrm{P}<0.05,{ }^{* *} \mathrm{P}<0.01$ and ${ }^{* * *} \mathrm{P}<0.001$, with comparisons

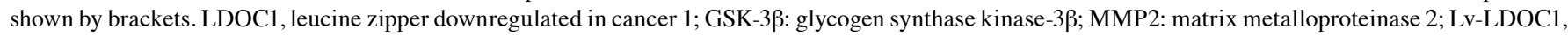
LDOC1-overexpressing cells; Lv-NC, negative control cells.

cycle arrest and immunofluorescence between HCT-116 cells and $\mathrm{Caco} 2$ cells, which may be associated with the different types of tumor cells and different degrees of malignancy. Although these experiments have fully verified the effects of LDOC1 on proliferation, metastasis and apoptosis of CRC cells in vitro, they lack further validation in vivo. In the following experiments, to further validate the hypothesis in vivo, the use of another xenograft model to detect the effects of LDOC1 on tumorigenesis and metastasis in nude mice should be conducted.

In conclusion, as a tumor suppressor gene, LDOC1 inhibits cell proliferation and promotes cell apoptosis in CRC; furthermore, it was determined that LDOC1 could inhibit metastasis of CRC cells via downregulation of the Wnt/ $\beta$-catenin signaling pathway. These observations provide the novel direction for molecular targeted therapy and prognosis of CRC. However, the present study has some deficiencies, including the lack of the expression levels of LDOC1 in normal colorectal cells, which will be compensated by further study.

\section{Acknowledgements}

The authors would like to thank the Chongqing Key Laboratory of Molecular Oncology and Epigenetics (Chongqing, China) for technical guidance.

\section{Funding}

No funding was received.

\section{Availability of data and materials}

All the data used and analyzed during study are available from the corresponding author upon reasonable request.

\section{Authors' contributions}

JJ, YL and ZJ made substantial contributions to the conception and design of the study. JJ performed the experiments and analyzed the data. YL participated in the collection of samples and the collation of data. JJ and YL were involved in the drafting of the manuscript. $\mathrm{ZJ}$ revised the study critically for important intellectual content. All authors have read and approved the final manuscript.

\section{Ethics approval and consent to participate}

All patients signed informed consent forms, and the present study was approved by the Ethics Committee of the First Affiliated Hospital of Chongqing Medical University (Chongqing, China). 


\section{Patient consent for publication}

Patients consented for publication.

\section{Competing interests}

The authors declare that they have no competing interests.

\section{References}

1. Torre LA, Bray F, Siegel RL, Ferlay J, Lortet-Tieulent J and Jemal A: Global cancer statistics, 2012. CA Cancer J Clin 65 : 87-108, 2015

2. Siegel RL, Miller KD, Fedewa SA, Ahnen DJ, Meester RG, Barzi A and Jemal A: Colorectal cancer statistics, 2017. CA Cancer J Clin 67: 177-193, 2017.

3. Bray F, Ferlay J, Soerjomataram I, Siegel RL, Torre LA and Jemal A: Global cancer statistics 2018: GLOBOCAN estimates of incidence and mortality worldwide for 36 cancers in 185 countries. CA Cancer J Clin 68: 394-424, 2018.

4. Luo Y, Tsuchiya KD, Il Park D, Fausel R, Kanngurn S, Welcsh P, Dzieciatkowski S, Wang J and Grady WM: RET is a potential tumor suppressor gene in colorectal cancer. Oncogene 32: 2037-2047, 2013

5. Nagasaki K, Manabe T, Hanzawa H, Maass N, Tsukada $T$ and Yamaguchi K: Identification of a novel gene, LDOC1, down-regulated in cancer cell lines. Cancer Lett 140: 227-234, 1999.

6. Zhao S, Wang Q, Li Z, Ma X, Wu L, Ji H and Qin G: LDOC1 inhibits proliferation and promotes apoptosis by repressing $\mathrm{NF}-\kappa \mathrm{B}$ activation in papillary thyroid carcinoma. J Exp Clin Cancer Res 34: 146, 2015.

7. Lee CH, Pan KL, Tang YC, Tsai MH, Cheng AJ, Shen MY, Cheng YM, Huang TT and Lin P: LDOC1 silenced by cigarette exposure and involved in oral neoplastic transformation. Oncotarget 6: 25188-25201, 2015.

8. Riordan JD and Dupuy AJ: Domesticated transposable element gene products in human cancer. Mob Genet Elements 3: e26693, 2013.

9. Camões MJ, Paulo P, Ribeiro FR, Barros-Silva JD, Almeida M, Costa VL, Cerveira N, Skotheim RI, Lothe RA, Henrique R, et al: Potential downstream target genes of aberrant ETS transcription factors are differentially affected in Ewing's sarcoma and prostate carcinoma. PLoS One 7: e49819, 2012.

10. Inoue M, Takahashi K, Niide O, Shibata M, Fukuzawa $M$ and Ra C: LDOC1, a novel MZF-1-interacting protein, induces apoptosis. FEBS Lett 579: 604-608, 2005.

11. Griesinger AM, Witt DA, Grob ST, Georgio Westover SR, Donson AM, Sanford B, Mulcahy Levy JM, Wong R, Moreira DC, DeSisto JA, et al: NF-אB upregulation through epigenetic silencing of LDOC1 drives tumor biology and specific immunophenotype in Group A ependymoma. Neuro Oncol 19: $1350-1360,2017$.

12. Thoompumkal IJ, Rehna K, Anbarasu K and Mahalingam S: Leucine zipper down-regulated in cancer-1 (LDOC1) interacts with guanine nucleotide binding protein-like 3-like (GNL3L) to modulate nuclear factor-kappa $\mathrm{B}(\mathrm{NF}-\kappa \mathrm{B})$ signaling during cell proliferation. Cell Cycle 15: 3251-3267, 2016.

13. Nagasaki K, Schem C, von Kaisenberg C, Biallek M, Rösel F, Jonat $\mathrm{W}$ and Maass N: Leucine-zipper protein, LDOC1, inhibits NF-kappaB activation and sensitizes pancreatic cancer cells to apoptosis. Int J Cancer 105: 454-458, 2003.

14. Buchholtz ML, Brüning A, Mylonas I and Jückstock J: Epigenetic silencing of the LDOC1 tumor suppressor gene in ovarian cancer cells. Arch Gynecol Obstet 290: 149-154, 2014.

15. Buchholtz ML, Jückstock J, Weber E, Mylonas I, Dian D and Brüning A: Loss of LDOC1 expression by promoter methylation in cervical cancer cells. Cancer Invest 31: 571-577, 2013.

16. Yong BC, Lu JC, Xie XB, Su Q, Tan PX, Tang QL, Wang J, Huang G, Han J, Xu HW, et al: LDOC1 regulates Wnt5a expression and osteosarcoma cell metastasis and is correlated with the survival of osteosarcoma patients. Tumour Biol: Feb 1, 2017 (Epub ahead of print). doi.org/10.1177/1010428317691188.

17. Chen X, Jia C, Jia C, Jin X and Gu X: MicroRNA-374a inhibits aggressive tumor biological behavior in bladder carcinoma by suppressing Wnt/ $\beta$-catenin signaling. Cell Physiol Biochem 48: $815-826,2018$.
18. Park HW, Kim YC, Yu B, Moroishi T, Mo JS, Plouffe SW, Meng Z, Lin KC, Yu FX, Alexander CM, et al: Alternative Wnt signaling activates YAP/TAZ. Cell 162: 780-794, 2015.

19. Zhang LZ, Huang LY, Huang AL, Liu JX and Yang F: CRIP1 promotes cell migration, invasion and epithelial-mesenchymal transition of cervical cancer by activating the $\mathrm{Wnt} / \beta$ catenin signaling pathway. Life Sci 207: 420-427, 2018

20. Yu R, Cai L, Chi Y, Ding X and Wu X: miR-377 targets CUL4A and regulates metastatic capability in ovarian cancer. Int J Mol Med 41: 3147-3156, 2018.

21. Ling DJ, Chen ZS, Zhang YD, Liao QD, Feng JX, Zhang XY and Shi TS: MicroRNA-145 inhibits lung cancer cell metastasis. Mol Med Rep 11: 3108-3114, 2015.

22. Wang YP, Guo PT, Zhu Z, Zhang H, Xu Y, Chen YZ, Liu F and Ma SP: Pleomorphic adenoma gene like-2 induces epithelial-mesenchymal transition via Wnt/ $\beta$-catenin signaling pathway in human colorectal adenocarcinoma. Oncol Rep 37: 1961-1970, 2017.

23. Tang X, Zha L, Li H, Liao G, Huang Z, Peng X and Wang Z: Upregulation of GNL3 expression promotes colon cancer cell proliferation, migration, invasion and epithelial-mesenchymal transition via the $\mathrm{Wnt} / \beta$-catenin signaling pathway. Oncol Rep 38: 2023-2032, 2017.

24. Kim HJ, Moon SJ, Kim SH, Heo K and Kim JH: DBC1 regulates Wnt/ $\beta$-catenin-mediated expression of MACC1, a key regulator of cancer progression, in colon cancer. Cell Death Dis 9: 831, 2018.

25. Livak KJ and Schmittgen TD: Analysis of relative gene expression data using real-time quantitative PCR and the 2(-Delta Delta C(T)) method. Methods 25: 402-408, 2001.

26. Tao Y, Tao T, Gross N, Peng X, Li Y, Huang Z, Liu L, Li G, Chen $X$ and Yang J: Combined effect of IL-12Rß2 and IL-23R expression on prognosis of patients with laryngeal cancer. Cell Physiol Biochem 50: 1041-1054, 2018.

27. Chen J: The cell-cycle arrest and apoptotic functions of p53 in tumor initiation and progression. Cold Spring Harb Perspect Med 6: a026104, 2016.

28. Patil M, Pabla N and Dong Z: Checkpoint kinase 1 in DNA damage response and cell cycle regulation. Cell Mol Life Sci 70: 4009-4021, 2013

29. Wang X, Zhu Y, Sun C, Wang T, Shen Y, Cai W, Sun J, Chi L, Wang H, Song N, et al: Feedback activation of basic fibroblast growth factor signaling via the $\mathrm{Wnt} / \beta$-catenin pathway in skin fibroblasts. Front Pharmacol 8: 32, 2017.

30. Cai T, Sun D, Duan Y, Wen P, Dai C, Yang J and He W: WNT/ $\beta$-catenin signaling promotes VSMCs to osteogenic transdifferentiation and calcification through directly modulating Runx2 gene expression. Exp Cell Res 345: 206-217, 2016.

31. Johnson IT and Belshaw NJ: Environment, diet and CpG island methylation: Epigenetic signals in gastrointestinal neoplasia. Food Chem Toxicol 46: 1346-1359, 2008

32. Hayden MS and Ghosh S: Regulation of NF- $\kappa$ B by TNF family cytokines. Semin Immunol 26: 253-266, 2014.

33. Yu L, Li L, Medeiros LJ and Young KH: NF- $\kappa$ B signaling pathway and its potential as a target for therapy in lymphoid neoplasms. Blood Rev 31: 77-92, 2017.

34. Shukla S, Shankar E, Fu P, MacLennan GT and Gupta S: Suppression of NF- $\kappa B$ and NF- $\kappa$ B-regulated gene expression by apigenin through $\mathrm{I} \kappa \mathrm{B} \alpha$ and IKK pathway in TRAMP mice. PLoS One 10: e0138710, 2015.

35. Prasad S, Ravindran J and Aggarwal BB: NF-kappaB and cancer: How intimate is this relationship. Mol Cell Biochem 336: 25-37, 2010.

36. Brentnall M, Rodriguez-Menocal L, De Guevara RL, Cepero E and Boise LH: Caspase-9, caspase-3 and caspase-7 have distinct roles during intrinsic apoptosis. BMC Cell Biol 14: 32, 2013.

37. Dai G, Zheng D, Wang Q, Yang J, Liu G, Song Q, Sun X, Tao C, Hu Q, Gao T, et al: Baicalein inhibits progression of osteosarcoma cells through inactivation of the Wnt/ $\beta$-catenin signaling pathway. Oncotarget 8: 86098-86116, 2017.

38. Kwon YJ, Baek HS, Ye DJ, Shin S, Kim D and Chun YJ: CYP1B1 enhances cell proliferation and metastasis through induction of EMT and activation of Wnt/ $\beta$-catenin signaling via Sp1 upregulation. PLoS One 11: e0151598, 2016.

39. Lee JM, Dedhar S, Kalluri R and Thompson EW: The epithelial-mesenchymal transition: New insights in signaling, development, and disease. J Cell Biol 172: 973-981, 2006. International (CC BY-NC-ND 4.0) License. 